\title{
Innovation model of relations between Russia and China in the context of science and educational cooperation
}

\author{
Yelena Ivukina* \\ Ural State University of Economics, 8 Marta/Narodnoy Voli St., 62/45, 620144 Ekaterinburg, Russia
}

\begin{abstract}
This article is devoted to the investigation of Russia-China higher education cooperation. Both countries are involved in the modernization process in the framework of the global educational environment, which stimulates the achievement of a high level of teaching and provides a variety of research forms and international experience in joint adaptation. Special attention is paid to three main constituencies of academic innovative cooperation namely students' engagement, lecturers and researchers' involvement and creation of joint universities and research centers with their definite purposes, current status and priorities respectively. The article makes recommendations in terms of strengthening the bilateral Russian-Chinese educational process and overcoming the barriers that arise in this alliance.
\end{abstract}

\section{Introduction}

Nowadays under the conditions of economic and social world community development, further science and technologies progress, each country is involved in increasing the requirements for the education system, content and methods of teaching. In general, a university aims at reproducing and transferring social experience due to the peculiar features of the social and economic systems. Thus an expansive international scientific cooperation and innovative capacity are viewed as priority goals in Russia and China in the framework of science and educational cooperation.

It is worth mentioning that under the conditions of obvious limitations in terms of extensive innovation models of Russian and Chinese economic development, the use of bilateral scientific and educational cooperation, focused on increasing the national innovation potential is of great interest. It is assumed, that modernization of an education system demands studying of different foreign countries experience. This article is devoted to the investigation of innovation model of relations between Russia and China in the context of scientific and educational cooperation.

${ }^{*}$ Corresponding author: esi99@mail.ru 


\section{Research methods}

This research paper is based on the implementation of the general scientific methods: generalization, deduction, a situational analysis as well as comparative and sampling methods, etc. Undoubtedly, the implementation of these research methods will contribute to submitting a profound analysis of objective advantages of each constituencies with their unique niches and features, referring to bilateral academic interaction in a broader scope. Three main areas of academic cooperation are identified as variables: attracting foreign student; attracting foreign lecturers and researchers; and establishing joint universities and research centers. Based on the situational analysis of the necessary resources and possible effects of these investigated areas, a conclusion is made about the priorities of academic cooperation and tasks within each area, i.e. about the "hierarchical arrangement" of variables [1]. In terms of a sampling method, in our research paper we use it for ranking Russia and China in the world by the education level index (see Table 1), where the first place corresponds to the highest indicator value, and the last one to the lowest [2].

Table 1. Ranking of countries in the world by the education level index

\begin{tabular}{|c|c|c|}
\hline Rating & Country & Index \\
\hline 1 & Germany & 0.946 \\
\hline$\ldots 33$ & Russia & 0.832 \\
\hline$\ldots 110$ & China & 0.636 \\
\hline$\ldots 189$ & Nigeria & 0.243 \\
\hline
\end{tabular}

Source: United Nations Development Program: Human Development Index (HDI): Education Index, 2019. [URL: hdr.undp.org.]

The World Education Index is a combined indicator of the United Nations Development Program (UNDP), measuring the achievements of a country in terms of the education level of its population by two key indicators: 1$)$ adult literacy index ( $2 / 3$ weight) and 2$)$ index of the total share of students receiving primary, secondary and higher education $(1 / 3$ of the weight). But it's worth highlighting, that such a versatile indicator possesses a number of limitations reflecting the quality of education itself, and on the other hand, this index does not take into account the foreign students, which may distort data for some small countries.

\section{Problem statement and discussion}

\subsection{Current status of Russian-Chinese educational cooperation}

In recent years, higher education cooperation between Russia and China is mainly concerned with strengthening their competitiveness in student and staff mobility, research cooperation, joint degree education provision, etc. As it is accepted by the scientific community worldwide, higher education in general, and in Russia and China particularly, coincides to great extent, embracing the following constituencies: 
- an increase in international reputation and competitiveness of both countries, which largely depends on intellectual capacity and technology as well as effective institution performance and the education organization itself;

- the opportunity to get a high-paid job and make a successful carrier;

- the possibility of getting a huge amount of information about universities, expanding the students' worldview;

- the growing demands for higher education by importing high quality education resources from both countries.

At present, the university' missions of teaching, research and economic development are evoking from being merely a facilitator for transferring technology to individual firms to being a force for fostering regional economic and social development [3].

The matter is that both universities operate in an innovative mode, assuming that the innovating process itself is a motivated, purposeful and conscious process for the creation, development, use and dissemination of modern (or modernized) ideas (theories, techniques, technologies, etc) that are relevant and adapted to these conditions and meet certain criteria [4]. On the other hand, Chinese and Russian universities are involved in the process of higher education internationalization, defined as a factor in the educational organization development and its subjects, which stimulates the achievement of a high level of teaching; provides a variety of research forms and design activities, co-adaptation of international experience, etc. [5]. Actually, when cooperating with Russian higher education, China is more concerned with importing advanced Russian education resources to enhance the capacity of its universities. Yet, China, has overtaken the United States in terms of total number of science publications. Indeed, both countries are on the verge of becoming global actors in science, technology and innovation. Nevertheless, we can also acknowledge some obstacles in this issue, including the following aspects: a lack of trust and mutual understanding between Russian and Chinese universities. In broader scope, China is still facing a dilemma between either to lose its educational sovereignty or to import advanced educational resources from Russia. The other issues embrace bilateral collaborative education provision, namely on quality assurance, determined by differences in aims for cooperation, financial commitments, and perception of quality between partners of both sides.

\subsection{Students' engagement: strengths and weaknesses}

According to the situational analysis, we should take into account the above-mentioned key areas of academic innovative cooperation (students' engagement, lecturers and researches' involvement and creation of joint universities and research centers) with their specific purposes, current status and priorities correspondingly.

Taking into consideration the students' engagement issue, its goal consists of expanding interaction in the area of non-linguistic specialties, focusing primarily not on the number of students and curricular but their quality, leading to the improvement of the graduates' career perspectives. Traditionally, the path to scientific, technical and innovative cooperation between both countries lies through the students' exchanges and mutual study of languages. About a third of Chinese students in Russian universities and the majority of Russian students in Chinese universities studied Russian and Chinese respectively. The choice of specialties can be related both to the interests of the students themselves and to the availability of places for foreigners in the relevant specialties at the universities. Moreover, Russian higher educational institutions are generally more willing to accept foreign students in non-linguistic specialties. Actually these specialties can be taught not only in Russian and Chinese, but also in English. Nowadays Russian and Chinese students 
are more interested in studying especially natural sciences alongside with technical and engineering specialties, contributing to achieving a progress in the sphere of scientific and innovative projects.

The education system in China is often determined as pragmatic, egalitarian, democratic and selected. As a matter of fact, admission to a Chinese university is considered as a very complicated process, determined by a strong competition among them, accounting from 200 to 300 people per place. According to statistics, there are more than 2 thousand universities, colleges and professional higher schools with 9,5 million people enrolled in studying process in China [6]. As far as the recent researches are concerned, Russia and China have reached an approximate parity in the number of students studying at each other's universities - about 20 thousand people from each country per year, i.e. approximately 40 thousand people in 2017 academic year [7]. Actually, the number of Chinese students studying abroad is still growing rapidly, with a compound annual growth rate of $13.9 \%$ over the last decade [8]. In terms of Russia, it faces the problems in attracting foreign students. Upon the whole, approximately 8 million students are accounted in the country whereas only 150 thousands, or $2 \%$ are foreigners [9]. Although Russia has a high reputation all over the world, its higher education market is far from being saturated. In fact, the world market of educational services has the following structure: US - 40\%, UK $15 \%$, France and Germany approximately $10 \%$ whereas Russia - about $2 \%$, etc.[10]. We can propose that this poor rating is determined by the following reasons: the language barrier; complicated procedures for obtaining visas; the complexity of practice admission and further employment; it is even impossible to get the policy of obligatory medical insurance for foreign citizens, the problem of attracting foreign students, etc.

The Chinese government has signed several agreements on mutual recognition of diplomas with 64 countries and regions, including Russia, Germany, Italy, England and others [11]. Thus the China's higher education system already deserves an international reputation.

The other key priority in terms of student engagement is characterized by improvement and expansion of graduates' career prospects. Profound studies justify that a country benefits most from investment in international education if foreign graduates remain employed in the country rather than return to their homeland [12]. Consequently, it is advisable to correspond the university openness policy for foreign students with the openness policy of the labor market for graduates in order to eliminate the bureaucratic barriers to graduates' employment. In fact, employment of Chinese graduates in Russia is more preferable.

\subsection{Academic staff and researchers' involvement: benefits and obstacles}

As it was mentioned above, the second key area of academic innovative cooperation is academic staff and researchers' involvement process, aimed at providing them with the opportunity to get acquainted with the scientific and educational systems of Russia and China. Therefore, it enables to establish working contacts in order to conduct joint projects in the sphere of $R \& D$. The third purpose embraces the optimization of program implementation due to the specialties diversification and exchange formats.

Investigating the current state of this process, it is worth pointing out a number of objective and subjective factors: an access of foreigners to the labor market; political and geographical priorities of academic cooperation, competition between national and international academic staff and the openness of universities to foreign lecturers and researches [13]. 
In accordance with the Chinese system, academic staff and researchers, coming from abroad, are identified as foreign specialists who get a work permit but it should be noticed that only few Russian citizens work in Chinese universities. Obviously, it is determined by two reasons: on the one hand, Chinese universities are oriented to the standards of recognized world leaders in the educational sphere (primarily the US), and on the other hand, nowadays Russia is still comparatively isolated from the world academic environment.

Recognition of the Russian $\mathrm{PhD}$ degree as the equivalent of the Western $\mathrm{PhD}$ (or Chinese «boshi») is another urgent issue. The fact is that Russian degree of Candidate of Sciences corresponds to the associate professor title, affecting the overall attractiveness of the Russian education system. Consequently, for Chinese academic staff it is more preferable to get a $\mathrm{PhD}$, without which they can hardly climb their career ladder.

\subsection{Creation of joint universities and research centers: challenges and opportunities}

Another priority of this article is to investigate the current state of research centers and joint universities in both countries. Cooperation with universities would sow the seeds of future research and attract employees; collaborating with national research institutes would gain them access to facilities [14]. As it turned out, there is a principle difference among research centers, joint universities and exchange programs for students and academic staff, taking into consideration some peculiarities of the Chinese education system. In fact, the Chinese system in the higher education sphere is reluctant to creating branches of foreign universities thus concentrating on the implementation of joint projects with Chinese institutional partners. To great extent, the process of choosing them is determined by the following criteria: prestige of the university on the educational market, geographical criterion, and interest of Chinese actors in cooperation with Russian ones.

\section{Conclusions}

Thus, taking into consideration the above-mentioned statements, it is worth making definite conclusions in the context of Russian-Chinese education cooperation.

First, in order to attract Chinese students to Russia and Russian student to China, it is necessary: to shift the focus from training programs' quantity to their quality; to concentrate on attracting students to non-linguistic (natural science, IT technologies, engineering, etc.) majors; to expand the graduates' career prospects.

Second, to attract academic staff, it is advisable: to encourage lecturers and researchers of both countries to establish working contacts for performing joint R\&D projects; to diversify opportunities for permanent and temporary employment of Russian and Chinese specialists in the educational institutions; to establish grant support for academic staff.

Third, for joint ventures and research centers development, is it recommended to: give priority to the most prominent projects; to be flexible in terms of designing educational programs, taking into account Russian and Chinese differences in the sphere of science and education.

\section{References}

1. E.M. Mora - Valentin, Ind. High. Educ., 14, 165 (2000) 
2. Education Index (2019). http:// hdr.undp.org/en/content/education-index

3. H. Etzkowitz, Sci. Public Policy, 29, 115 (2020)

4. P. Shimko, Bul. Unecon Series Economy, 3, 337 (2008)

5. A. Shumeyko, Modern problems of Science and Education, 6, 532 (2015)

6. O.V.Vasyukhin, Q. Xu, Problems and prospects of economics and management, 3, 79 (2014)

7. N. Warikoo, U. Allen, Stud. High. Educ., 45, 2398 (2019)

8. Y.Z. Cai, Front. Educ. China, 9, 175 (2014)

9. P. Antipov P. Optima Study Int. Educ. Lang., 2, 12 (2013)

10. K.Yu. Burtzeva Sci.Vector TSU, 2, 63 (2014)

11. S.-H. Yun, Int. J. Comm., 9, 710(2015)

12. J. Bergerhoff., L. Borghans, P.K. Seegers, T.ban Venn, IZA J, Eur. Labor Stud., 2, 3 (2013)

13. H. Horta, J.M.Santos, Stud. High. Educ., 45, 2382 (2020)

14. Y. Caloghirou, N.S. Vonortas, S. Ioannides, Sci. Public Policy, 29, 82 (2002) 